d

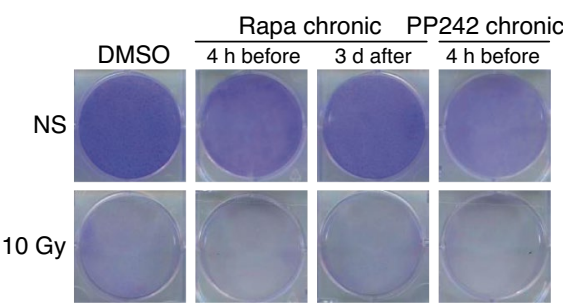

Original
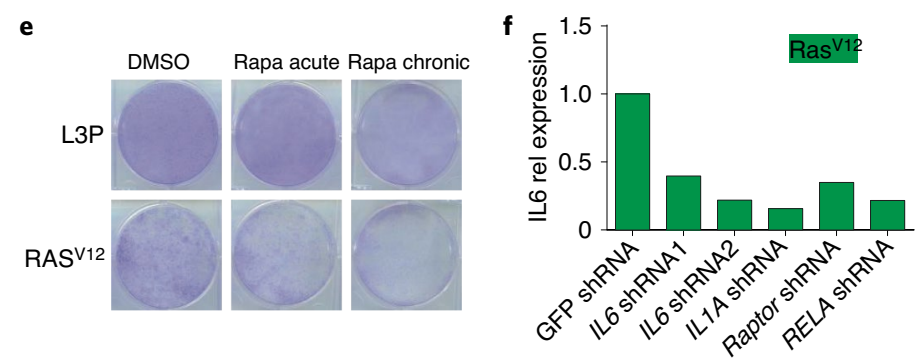

g
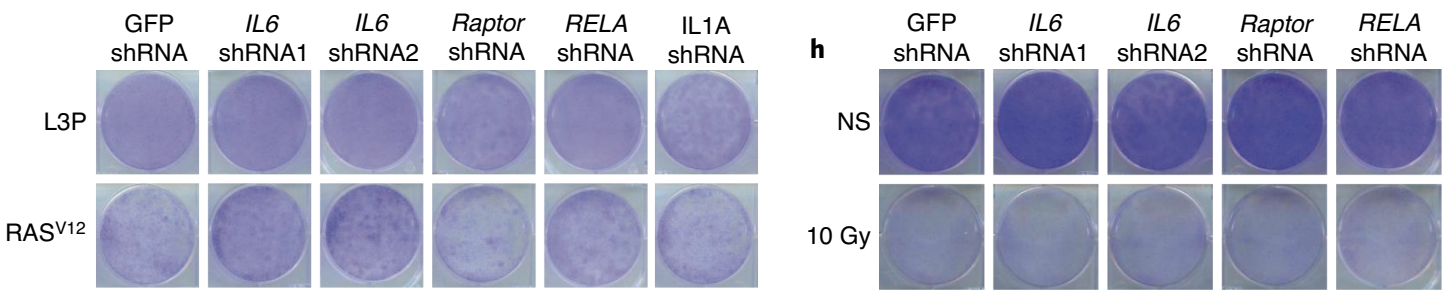

d
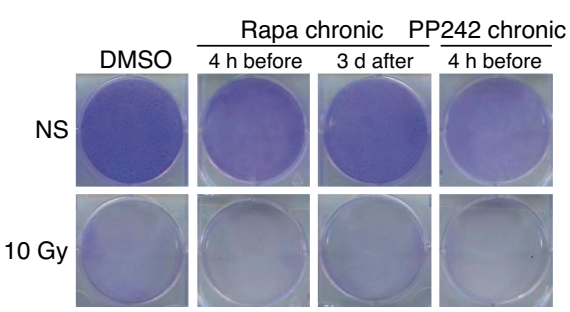

e

\title{
Corrected
}
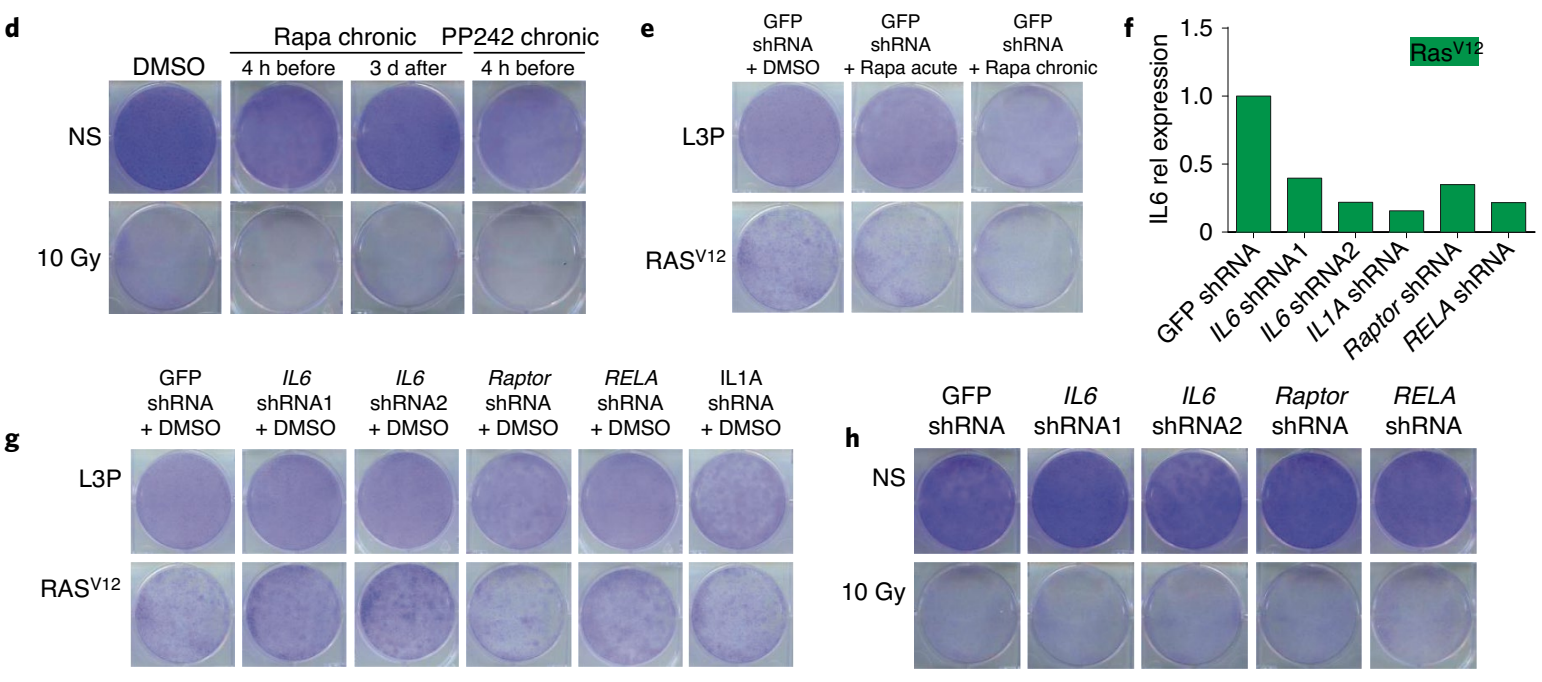

RELA

ShRNA
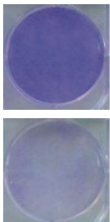

Fig. 6 | Original and Corrected.

Published online: 13 April 2021

https://doi.org/10.1038/s41556-021-00655-4

๑ The Author(s), under exclusive licence to Springer Nature Limited 2021

\section{Author Correction: Optogenetic manipulation of cellular communication using engineered myosin motors}

Zijian Zhang, Nicolas Denans (1), Yingfei Liu, Olena Zhulyn, Hannah D. Rosenblatt, Marius Wernig (i) and Maria Barna (D)

Correction to: Nature Cell Biology https://doi.org/10.1038/s41556-020-00625-2, published online 1 February 2021

In the version of this Technical Report originally published, there was a labelling error in Fig. 6. In Fig. 6e, the labels "24 h light" and " 24 $h$ dark" should be swapped in place of each other. The errors have been corrected.

Published online: 8 April 2021

https://doi.org/10.1038/s41556-021-00675-0

(c) The Author(s), under exclusive licence to Springer Nature Limited 2021 